\title{
Certified Smoking Cessation Units in Spain: High Potential for Detection of Undiagnosed Chronic Obstructive Pulmonary Disease and Profile of Newly Diagnosed Cases
}

This article was published in the following Dove Press journa:

International Journal of Chronic Obstructive Pulmonary Disease

Juan-Antonio Riesco-

Miranda (iD) ${ }^{1,2}$

Segismundo Solano-Reina (iD ${ }^{3}$

Carlos Rábade-Castedo (iD ${ }^{4}$

José-Ignacio de Granda-Orive ${ }^{5}$

Esther Pastor-Esplá ${ }^{6}$

Marcos García-Rueda ${ }^{7}$

Francisco-Javier Callejas-

Gonzalez (iD) 8

Ángel Azpeitia-Anadón ${ }^{9}$

Silvia Mas ${ }^{10}$

Carlos-Andrés Jiménez-Ruiz ${ }^{11}$

'Servicio de Neumología, Hospital Universitario de Cáceres, Cáceres, Spain; ${ }^{2}$ CIBERES, Madrid, Spain; ${ }^{3}$ Servicio de Neumología, Hospital General

Universitario Gregorio Marañón, Madrid, Spain; ${ }^{4}$ Servicio de Neumología, Hospital Clínico Universitario de Santiago de Compostela, Santiago de Compostela, Spain; ${ }^{5}$ Servicio de Neumología, Hospital Universitario Doce de Octubre,

Universidad Complutense de Madrid, Madrid, Spain; ${ }^{6}$ Servicio de Neumología, Hospital Universitario San Juan de Alicante, Alicante, Spain; ${ }^{7}$ Servicio de Neumología, Hospital Universitario Carlos Haya, Málaga, Spain; ${ }^{8}$ Servicio de Neumología, Complejo Hospitalario Universitario de Albacete, Albacete, Spain; ${ }^{9}$ Departamento Médico Labs, Esteve S.A, Barcelona, Spain;

${ }^{10}$ Universidad Pompeu Fabra, Barcelona, Spain; ' Unidad Especializada de

Tabaquismo, Hospital Clínico

Universitario, Madrid, Spain

Correspondence: Silvia Mas

Universitat Pompeu Fabra, Campus Poble

Nou, Roc Boronat I38, Barcelona, 080I8,

Spain

Email silviamas.md@gmail.com
Purpose: Smokers attending smoking cessation units (SCUs) may offer a unique opportunity for early recognition of undiagnosed chronic obstructive pulmonary disease (COPD). We aimed at assessing the impact of SCUs on the early diagnosis of COPD and describing the clinical and smoking profile of newly-diagnosed COPD cases at SCUs certified by the Spanish Society of Respiratory Diseases and Thoracic Surgery (SEPAR).

Patients and Methods: A multicenter cross-sectional observational cohort study (DIPREPOQ study) was performed in eight SEPAR-certified SCUs in Spain. Adult current smokers with no previously diagnosed respiratory disease and having one o more respiratory symptoms were included. Lung functional tests were performed and previously undiagnosed COPD cases were identified and characterized based on national guidelines.

Results: Out of 401 individuals newly attending the SCUs, 252 participants were included and 73 (28.9\%) met the definition of previously undiagnosed COPD. A characterization of patients with COPD being newly recognized in SCUs showed: age (mean \pm SD) $61 \pm 9$ years; men $59 \%$; active work status 53.1\%; functional class I/II dyspnea $82.8 \%$, GOLD state mild/moderate/severe $57 \%$ / $31 \% / 12 \%$; non-exacerbators $90 \%$, CAT $14 \pm 4$; emphysema in X-rays $40 \%$. Most common comorbidities were cardiovascular and psychiatric (anxiety and depression) ones. Usual smoking history included a lengthy smoking history ( $41 \pm 9$ years) and a current consumption of $24 \pm 9$ cigarettes/day.

Conclusions and Implications: Consistently certified SCUs can have a substantial contribution to early diagnosis of COPD. A typical profile of newly detected cases is reported, with most patients being men at their early sixties, with mild symptoms and with high and lengthy smoking history. Our study reports a high usefulness of lung functional tests to detect undiagnosed COPD in appropriately selected participants attending SCUs at a large national scale, using a standardized methodology. This is likely to be facilitated by the certification of SCUs using well-defined requirements by national scientific societies.

Keywords: health consequences, smoking, chronic obstructive pulmonary disease, smoking cessation unit

\section{Introduction}

In spite of some intensive efforts to reduce tobacco use, the prevalence of smoking remains high and tobacco is still a leading preventable cause of death. In Spain (with an adult [15 to 64-years-old] population of $28,472,557){ }^{1}$ a nation-wide survey showed that about $34 \%$ of adults were current smokers in 2017 . This

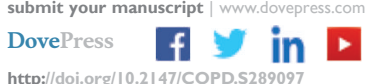


means an increase of 3.2 points over the prevalence in $2015 .^{2}$ In $2016,56,124$ deaths were attributed to tobacco consumption, $84 \%$ in men $(47,000)$, and $50 \%$ in the population aged over 74 (27,795). Overall, 50\% of SAM (smoking-attributable mortality) was due to cancer $(28,281), 65 \%$ of which was lung cancer. One in 4 attributable deaths $(13,849)$ occurred before the age of 65 . One in 7 deaths in Spain in 2016 was attributable to smoking. This estimation of SAM clearly highlights the great impact of smoking on mortality in Spain, mainly due to lung cancer and chronic obstructive pulmonary disease. ${ }^{3}$

Over the last two decades, a network of smoking cessation units (SCUs) has been developed in Spain based on recommendations ${ }^{4}$ and certification ${ }^{5,6}$ by SEPAR (Spanish Society of Respiratory Diseases and Thoracic Surgery).

Chronic obstructive pulmonary disease (COPD) is an increasing global public health issue and is predicted to be the third leading cause of death in 2030..$^{7,8}$ In Spain, prevalence of known COPD is $10.2 \%$ and, as found at a global scale, ${ }^{9}$ COPD is much underdiagnosed. ${ }^{10}$ The absolute risk of developing COPD among continuous smokers in the long term can reach $25 \%{ }^{11}$ Thus, smokers attending SCUs may offer a unique opportunity for early recognition of undiagnosed COPD.

We aimed at assessing the impact of SCUs on the early diagnosis of COPD and to describe the clinical and smoking profile of newly-diagnosed COPD cases at SEPARcertified SCUs in Spain.

\section{Methods}

\section{Design}

A multicenter cross-sectional observational cohort study (DIPREPOQ study) was carried out in patients attending SCUs. Eight SEPAR-certified SCUs from different Spanish areas were willing to participate in the study. All patients attending the SCUs over a 12-months period (from April 15, 2017 to April 15, 2018) and meeting all inclusion criteria were offered enrolment. Six-month preliminary results are reported.

\section{Criteria for Inclusion}

Main inclusion criteria were: current smokers aged $\geq 35$ years, with a pooled tobacco use of $\geq 10$ pack-years and at least one respiratory symptom (cough and/or sputum, chest rales, $\geq 2$ respiratory events in previous year, dyspnea, intolerance to physical activity, any symptom requiring lung function tests). ${ }^{12}$ Individuals with a previous COPD diagnosis, asthma or any chronic respiratory disease, clinical and/or hemodynamic instability within previous 8 weeks, or unable to perform spirometry tests were excluded.

\section{Variables with Definitions}

Sociodemographic data and smoking history were recorded in the first visit. Lung functional tests (LFT) were performed within 8 weeks after first visit; SEPAR guidelines for LFT were followed. Data on smoking history and status, 6-item Fagerström Test for Cigarette Dependence (FTCD), ${ }^{13}$ Hospital Anxiety and Depression Scale (HADS), ${ }^{14} \mathrm{CO}$ in exhaled breath test, and carboxyhemoglobin $(\mathrm{COHb})$ level were recorded.

A Carefusion Jaeger FlowScreen device with SentrySuite V2.15 (Carefusion, Yorba Linda, CA, USA) was used for lung functional tests, using methods currently recommended by SEPAR, ERS, and ATS. ${ }^{15,16}$ COPD cases were defined by a post-bronchodilator forced expiratory volume in the first second (FEV1)/forced vital capacity (FVC) ratio $<70 \%$ based on national guidelines. ${ }^{12}$ In patients with COPD, the following characteristics were also recorded: COPD Assessment Test (CAT), ${ }^{17}$ modified Medical Research Council (mMRC) Dyspnea Scale (0 to 4), ${ }^{18}$ number of exacerbations in previous year; GOLD stage; ${ }^{19}$ clinical profile based on Spanish COPD guidelines (GesEPOC) ${ }^{12}$ (nonexacerbator, non-exacerbator with emphysema, exacerbator with chronic bronchitis, mixed COPD-asthma); immunization history, and co-morbidities. Additional tests included chest X-ray, 6 minutes walking test (6MWT), ${ }^{20}$ prognostic COPD BODE index ${ }^{20}$ ( 0 to 4$)$, and BODEx $(\geq 5$ versus $<5)$.

\section{Statistical Analysis}

All data were collected and entered in a database by designated specifically trained physicians in each center.

Based on previous data ${ }^{10,21}$ and on the investigators' experience, expected prevalence of COPD in smokers attending SCUs was estimated at $20 \%$. For a $5 \%$ precision in prevalence estimation and a 95\% confidence level, 246 participants were required. Categorical variables were shown in number and percentage, and continuous variables were shown in mean \pm standard deviation (SD) or median (interquartile range; IQR) for descriptive statistics. Parametric tests (Student's $t$-test) were used to compare continuous variables based on their normal distribution, and chi-squared tests (with Yates' correction if applicable) were used for categorical variables, in exploratory 
comparisons between patients with newly diagnosed COPD versus COPD-free participants, and between participants with $\leq 20$ versus $>20$ pack-years.

\section{Ethical Committee}

Written informed consent was obtained from all participants. Data were de-identified and all study procedures complied with the latest version of the Declaration of Helsinki as per the International Guidelines for Ethical Review of Epidemiological Studies (CIOMS, Geneva, 1991). As recommended by SEE (Spanish Society of Epidemiology), the study was approved by the Ethics Committee of the Hospital Universitario Doce de Octubre, Madrid, Spain (17/213 - SEPAR-2017-01).

\section{Results}

Participating SCUs were located in different Spanish areas (Albacete, Alicante, Cáceres, Madrid (3), Málaga, Santiago de Compostela). The proportion of participants from each SCU is shown in Figure 1. All participating SCUs were certified by SEPAR.

Out of 401 individuals newly attending the 8 SCUs during a 6-month period, $213(53.1 \%)$ were men; mean $( \pm \mathrm{SD})$ age was $55 \pm 10.2$ years (range, $21-90$ years). Most of them were European Caucasians (98\%), and only a low proportion (19\%) lived alone. Their level of education was as follows: higher university $22 \%$, technical $17 \%$, secondary $22 \%$, primary $36 \%$, none $3 \%$. Occupational details: active workers $56 \%$, early retirees $24 \%$, unemployed workers $7 \%$, housework $7 \%$, disabled $3 \%$, sick leave $3 \%$.

The number of participants meeting the inclusion criteria was $252(63 \%)$, with the main reasons for exclusion being absence of respiratory symptoms $15 \%$, previous COPD diagnosis $16 \%$, asthma $5 \%$, and unable to perform LFT $1 \%$. The number of participants included achieved the sample size requirements and our findings in such participants are presented in the current report.

Out of 252 participants, 73 (28.9\%) met the definition of previously undiagnosed COPD (Figure 1). Sociodemographic and clinical characteristics and smoking history details of patients with an early COPD diagnosis in SCUs are shown in Table 1. A typical profile for patients with COPD being newly recognized in SCUs was as follows: a man in his early sixties, with an active work status, having functional class I/II dyspnea, nonexacerbator, and showing symptoms in CAT and emphysema in X-rays. Most common co-morbidities were cardiovascular and psychiatric (anxiety and depression) ones. Usual smoking history included a lengthy smoking duration (more than 40 years) and a current use of $\geq 20$ cigarettes per day, with predominantly negative reward. The number of previous attempts to quit smoking was usually low and most patients used drug therapy for smoking cessation, with nicotine replacement therapy being the most common one.

Table 2 shows the characteristics of participants with $\leq 20$ and $>20$ pack-years. Although COPD diagnosis rate was numerically higher in participants with $>20$ packyears, the difference did not achieve statistical significance. Sociodemographic characteristics were similar in both groups, except for a significantly older age in patients with a heavier smoking history.

When compared to COPD-free participants in exploratory analyses (Table 1), no significant differences in nicotine dependence were found in patients with a newly diagnosed COPD. Patients in whom COPD was ruled out were significantly younger $(\mathrm{p}<0.0001)$, and most of them held a job (76\% versus $53.1 \%$ in COPD patients, $\mathrm{p}<0.0001)$. Comorbidities, particularly hypertension and depression, were significantly more common in patients with a newly diagnosed COPD $(54.5 \%$ versus $36 \%, \mathrm{p}<0.0001)$. The most relevant difference was a longer smoking history and a higher number of pack-years in patients in whom COPD was found $(\mathrm{p}<0.0001) . \mathrm{CO}$ in exhaled breath and carboxyhemoglobin levels were higher in COPD-free patients (both $\mathrm{p}<0.05$ ).

\section{Discussion}

Our findings show a high prevalence (29\%) of undiagnosed COPD in smokers attending SCUs in Spain. Since participants were enrolled at 8 SCUs across the country, the results are likely to be fairly representative for Spain. Such COPD screening strategy in people attending smoking cessation clinics was previously suggested by Diez et al in a single-center study, with a lower $7.3 \%$ yield in detecting undiagnosed cases. ${ }^{22}$ To our knowledge, the current study is the first one to report LFT usefulness in appropriately selected participants at a large national scale, using a standardized methodology. This is facilitated by the certification of SCUs using well-defined requirements. ${ }^{4-6}$ The benefit of early COPD detection should be taken into account in future cost-effectiveness studies of SCUs.

In our study, straightforward and easy to implement criteria for diagnostic suspicion suggested by Spanish guidelines on COPD (GesEPOC) ${ }^{12}$ were used: adult smokers or former smokers of more than 10 packs-years having respiratory symptoms. Importantly, apart from those with an existing diagnosis 


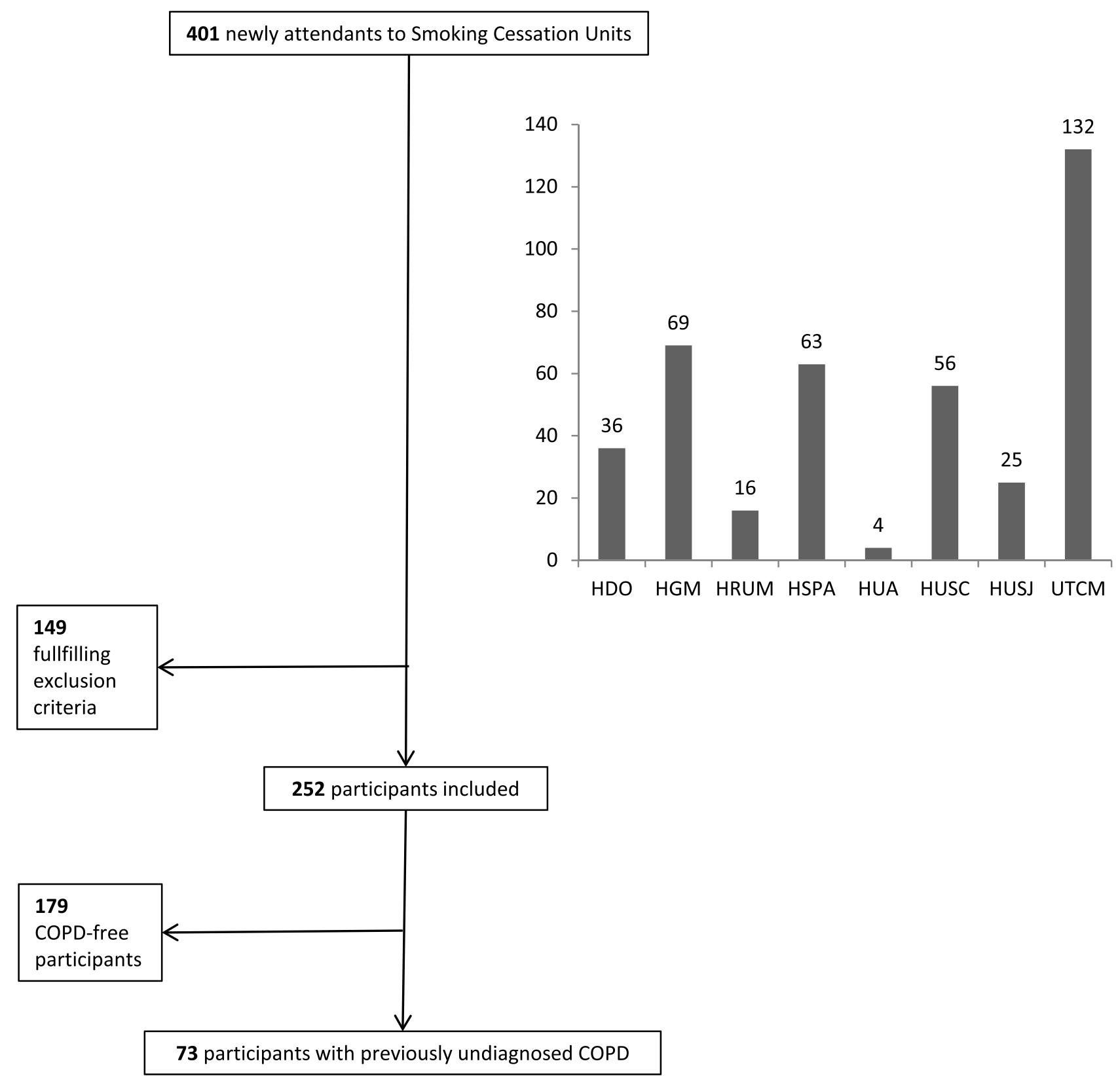

Figure I Distribution of participants from the 8 participating smoking cessation units in Spain.

Abbreviations: HDO, Hospital 12 de Octubre (Madrid); HGM, Hospital Gregorio Marañón (Madrid); HUSC, Hospital Clínico Universitario Santiago de Compostela; HCH, Hospital Carlos Haya (Málaga); HUSJ, Hospital San Juan de Alicante; HUA, Hospital Universitario de Albacete; UTCM, Unidad de Tabaquismo de la Comunidad de Madrid; HSPA, Hospital San Pedro de Alcántara (Cáceres).

of a respiratory disease, very few participants were excluded from LFT screening for COPD in our study. However, some studies have suggested that respiratory symptoms are not suitable as a criterion when screening for early COPD, and that testing all patients could be a more cost-effective strategy. ${ }^{23}$ Further studies are needed on methods to select patients for COPD screening.

We could not confirm that the probability of a new diagnosis of early COPD was significantly higher in participants with $>20$ pack-years, as suggested by some large population studies. ${ }^{24}$ This is probably due to the limited number of participants in a cohort study not aiming at proving such relationship. Taking into account the high potential for COPD detection in smokers attending SCUs, use of early predictive markers such as those recently reported based on the association between the exposure to some nicotine metabolites and COPD diagnosis, appears promising. ${ }^{25}$ The potential benefits of smoking cessation and varenicline use to improve lung 
Table I Main Sociodemographic and Clinical Characteristics and Smoking History Details in 73 Patients with a Previously Unsuspected COPD Diagnosis and 179 Patients in Whom COPD Diagnosis Was Ruled Out, Among Participants Newly Attending Smoking Cessation Units in Spain. Unless Otherwise Stated, Percentages Represent Proportion of Patients

\begin{tabular}{|c|c|c|c|}
\hline \multirow[t]{2}{*}{ Characteristics } & \multirow{2}{*}{$\begin{array}{l}\text { New COPD Diagnosis } \\
(n=73)\end{array}$} & No COPD & \multirow[t]{2}{*}{$\mathbf{p}$} \\
\hline & & $(n=179)$ & \\
\hline \multicolumn{4}{|l|}{ Sociodemographic characteristics } \\
\hline Age, mean $\pm S D$, years & $61 \pm 9$ & $53 \pm 8$ & $<0.0001$ \\
\hline \multicolumn{4}{|l|}{ Sex, n (\%) } \\
\hline Men & $43(59 \%)$ & $100(40 \%)$ & n.s. \\
\hline Women & 30 (41\%) & 78 (3।\%) & n.s. \\
\hline Level of education Primary education, \% & $59.1 \%$ & $55 \%$ & n.s. \\
\hline Current occupation Active work status, \% & $53.1 \%$ & $76 \%$ & $<0.0001$ \\
\hline \multicolumn{4}{|l|}{ Clinical characteristics - COPD } \\
\hline CAT, mean $\pm \mathrm{SD}$ & $14 \pm 4$ & NA & \\
\hline \multicolumn{4}{|l|}{ Presence of dyspnea, \% } \\
\hline Dyspnea & $82.8 \%$ & NA & \\
\hline No dyspnea & $17.2 \%$ & NA & \\
\hline mMRC functional dyspnea score & | or II & NA & \\
\hline \multicolumn{4}{|l|}{ GOLD stage, \% } \\
\hline Mild & $57 \%$ & NA & \\
\hline Moderate & $31 \%$ & NA & \\
\hline Severe & $12 \%$ & NA & \\
\hline GesEPOC phenotype Non-exacerbator, \% & $90 \%$ & NA & \\
\hline Emphysema in X-rays, \% & $40 \%$ & NA & \\
\hline \multicolumn{4}{|l|}{ Clinical characteristics - Comorbidities } \\
\hline$\geq 2$ co-morbidities, $\%$ & $54.5 \%$ & $36 \%$ & $<0.0001$ \\
\hline \multicolumn{4}{|l|}{ Main medical co-morbidities, \% } \\
\hline Hypertension & $53.8 \%$ & $21.8 \%$ & $<0.0001$ \\
\hline Dyslipidemia & $45.8 \%$ & NA & \\
\hline \multicolumn{4}{|l|}{ Main psychiatric co-morbidities, \% } \\
\hline Depression & $37 \%$ & $27 \%$ & $<0.01$ \\
\hline Anxiety & $28 \%$ & $26.6 \%$ & n.s. \\
\hline \multicolumn{4}{|l|}{ Smoking details } \\
\hline Duration of smoking, mean $\pm S D$, years & $41 \pm 9$ & $35 \pm 10$ & $<0.0001$ \\
\hline Number of cigarettes/day, mean \pm SD & $24 \pm 9$ & $20 \pm 8$ & n.s. \\
\hline Smoking history, mean $\pm S D$, pack-years & $49 \pm 19$ & $35 \pm 20$ & 0.000 \\
\hline Fagerström test score, mean \pm SD & $6.1 \pm 2.4$ & $6.3 \pm 1.8$ & n.s. \\
\hline $\mathrm{CO}$ in exhaled breath test, ppm & $17.7 \pm 9.1$ & $20 \pm 10.5$ & 0.044 \\
\hline Carboxyhemoglobin, \% of total $\mathrm{Hb}$ & $3.2 \pm 1.4$ & $4.1 \pm 3.6$ & 0.042 \\
\hline Any previous attempts to quit smoking, \% & $65.2 \%$ & $69.2 \%$ & n.s. \\
\hline Drug therapy for smoking cessation, $\%$ & $52.2 \%$ & $49.07 \%$ & n.s. \\
\hline
\end{tabular}

Abbreviations: CAT, COPD Assessment Test; mMRC, modified Medical Research Council (mMRC) Dyspnea Scale; GOLD, Global Initiative for Chronic Obstructive Lung Disease; GesEPOC, Spanish COPD guidelines; NA, not available (data not recorded in non-COPD patients); n.s., non significant. 
Table 2 COPD Diagnosis and Main Characteristics of Participants by Smoking History

\begin{tabular}{|c|c|c|c|}
\hline \multirow[t]{2}{*}{ Characteristics } & $\begin{array}{l}\leq 20 \text { Pack- } \\
\text { Years }\end{array}$ & $\begin{array}{l}>20 \text { Pack- } \\
\text { Years }\end{array}$ & \multirow[t]{2}{*}{$\mathbf{p}$} \\
\hline & $(n=24)$ & $(n=228)$ & \\
\hline \multicolumn{4}{|l|}{ Diagnosis, n (\%) } \\
\hline No COPD & 21 (87.5\%) & 158 (69.3\%) & \\
\hline COPD & 3 (I2.5\%) & 70 (30.7\%) & n.s. \\
\hline \multicolumn{4}{|l|}{$\begin{array}{l}\text { Sociodemographic } \\
\text { characteristics }\end{array}$} \\
\hline $\begin{array}{l}\text { Age (years), mean } \pm \\
\text { SD }\end{array}$ & $46.5 \pm 10.4$ & $56.4 \pm 8.4$ & $<0.0001$ \\
\hline \multicolumn{4}{|l|}{ Sex, n (\%) } \\
\hline Men & $12(50 \%)$ & $|3|$ (58\%) & \\
\hline Women & 12 (50\%) & 96 (42\%) & n.s. \\
\hline
\end{tabular}

Abbreviation: COPD, chronic obstructive pulmonary disease.

function parameters in COPD patients have been reported. ${ }^{26}$ The importance of starting therapy in an early COPD or even a pre-COPD phase to improve prognosis has been recently reported and specific measures have been suggested. ${ }^{27} \mathrm{COPD}$ detection by SCUs at an early stage could be useful to select patients requiring such an early treatment.

Smokers attending a SCU are particularly aware of the potential health risks of smoking. Thus, they are likely to better adhere to medical and lifestyle therapy when being diagnosed with COPD at the time of initiating a program to quit smoking. A typical profile for patients in whom a COPD diagnosis is established in SCUs is: a man in his early sixties, with functional dyspnea class I/II, showing mild-to-moderate symptoms and non-exacerbator. A majority of cases were in a mild GOLD stage, followed by moderate ones. Such an early diagnosis has been recommended to help delaying COPD progression. ${ }^{28}$ The high frequency of cardiovascular comorbidities confirms recent findings in SCUs. ${ }^{29}$

Comparisons of patients newly diagnosed with COPD versus COPD-free smokers should be taken as exploratory results due to the study design. We found smokers in whom COPD was ruled out to be younger and actively working, with no differences in educational level, whereas comorbidities, including hypertension and depression, were more common in patients with COPD. Smoking history showed clear-cut differences between both subgroups. Heavier smoking history seen in newly diagnosed participants versus COPD-free smokers is consistent with the fact of smoking being a key risk factor for COPD. COPD patients had been smokers for a longer time, which explains their higher pack-year index, with the number of cigarettes per day being similar in both subgroups. $\mathrm{CO}$ in exhaled breath test and carboxyhemoglobin were higher in patients not having COPD; this could be due to the impact of altered lung mechanics in COPD on inhalation. No differences were found in nicotine dependence as measured by the Fagerström test.

Our study has some limitations. Firstly, not being a population-based study, results are only applicable to the use of screening tools in SCUs using the methods certified in Spain. Secondly, air pollution has an impact on COPD development and may vary in different areas, which may also limit the extrapolation of our results to other settings. And thirdly, we did not assess the potential clinical benefit of early COPD detection in our patients.

\section{Conclusion}

In conclusion, consistently certified SCUs can have a substantial contribution to early diagnosis of COPD. A typical profile of newly detected cases is reported, with most patients being men at their early sixties, with mild symptoms and with large and lengthy smoking history.

\section{Acknowledgments}

The authors are grateful to Ricardo Pereira (data manager) Ana Nacarino (statistical analysis) and Ana Landines for editing the manuscript and providing editorial assistance.

\section{Funding}

The study has been carried out within the integrated SEPAR research program with the sponsorship of Laboratorios Esteve through an unrestricted grant. The funder had no role in the conception of the study, the execution of the field work, the collection of information, the analysis of the results, the preparation or approval of the final version of the article, or the decision to submit it for publication.

\section{Disclosure}

JARM has received honoraria for lecturing, scientific advice, participation in clinical studies or writing for publications for (alphabetical order): AstraZeneca, Boehringer Ingelheim, Chiesi, Laboratorios Esteve, Faes, Gebro, GSK, Menarini, Pfizer, and Rovi, outside the submitted work. CRC has received honoraria for lecturing, scientific advice, participation in clinical studies or writing for publications for pharmaceutical companies, such as Laboratorios Esteve, GSK, Menarini Mundi-Pharma, Novartis, Pfizer, and Teva Pharmaceutical. JIGO has received honoraria for lecturing, scientific advice, participation in clinical studies or writing for publications for 
(alphabetical order): AstraZeneca, Chiesi, Esteve, Faes, Gebro, Menarini, Pfizer, and Rovi. EPE has received lecture fees and/ or support for conference attendance from several pharmaceutical companies, such as Chiesi, Boehringer Ingelheim, Menarini, Pfizer, Novartis, Laboratorios Esteve, Teva Pharmaceutical, Ferrer, or Rovi. FJCG has received lecture fees, consultancy fees and/or support for conference attendance from several pharmaceutical companies, such as GlaxoSmithKline, Chiesi, Boehringer Ingelheim, Mundipharma, Menarini, Pfizer, Novartis, Laboratorios Esteve, Teva Pharmaceutical, Ferrer, Rovi, Roche, Astra Zeneca, Bial, Actelion, Grifols, CSL Behring, Faes Farma, and Gebro Pharma. CAJ-R has received honoraria for lecturing, scientific advice, participation in clinical studies or writing for publications for (alphabetical order): Gebro, Menarini and Pfizer. AAA is full-time employee at Laboratorios Esteve, Spain. The remaining authors report no conflicts of interest to be disclosed in this work.

\section{References}

1. INE. Cifras de Población 1-1-2017 y Estadística Migraciones 2016 (Provisionales) (2/16) Evolución Del Crecimiento Anual de La Población de España (2012-2016). Porcentajes; 2017 [Population figures 1-1-2017 and (interim) migration statistics (2/16) Course of Annual Growth of Population in Spain (2012-2016). Percent values, 2017]. Available from: http://www.ine.es/prensa/cp_2017_p.pdf. Accessed January 26, 2021.

2. Ministerio de Sanidad de España. Encuesta sobre alcohol y drogas en España (EDADES), 1995-2017; Published 2017 [Survey on alcohol and drugs in Spain (EDADES), 1995-2017]. Available from: https:// pnsd.sanidad.gob.es/profesionales/sistemasInformacion/ sistemaInformacion/pdf/EDADES_2017_Informe.pdf. Accessed September 9, 2020.

3. Pérez-Ríos M, Schiaffino A, Montes A, et al. Smoking-attributable mortality in Spain in 2016. Arch Bronconeumol. 2020;56:9. doi:10.1016/j.arbres.2019.11.021

4. Jiménez-Ruiz CA, Solano Reina $S$, Barrueco Ferrero $M$, et al. Recomendaciones para la organización y funcionamiento de las unidades especializadas en tabaquismo [Recommendations for organization and operation of specialized smoking units]. Arch Bronconeumol. 2001;37(9):382-387. doi:10.1016/S0300-2896(01)78819-9

5. Jiménez Ruiz CA, Manzano JR. La acreditación de las Unidades Especializadas en Tabaquismo [Accreditation of Specialized Smoking Units]. Arch Bronconeumol. 2020;56(9):59-60. doi:10.1016/j.arbres.2019.11.021

6. SEPAR. Guía SEPAR para la actualización de unidades especializadas en Tabaquismo [SEPAR Guidelines for updating specialized smoking units]. Available from: https://issuu.com/separ/docs/guia_separ_acreditacion_uni dades_de tabaquismo. Accessed August 21, 2020.

7. Mathers CD, Loncar D. Projections of global mortality and burden of disease from 2002 to 2030. PLoS Med. 2006;3(11):e442. doi:10.1371/ journal.pmed.0030442

8. World Health Organization. World health statistics 2008; 2008. Available from: https://www.who.int/whosis/whostat/EN_WHS08_ Full.pdf?ua=1. Accessed August 22, 2020.

9. Lamprecht B, Soriano JB, Studnicka M, et al. Determinants of underdiagnosis of COPD in national and international surveys. Chest. 2015;148(4):971-985. doi:10.1378/chest.14-2535
10. Soriano JB, Miravitlles M, Borderías L, et al. Diferencias geográficas en la prevalencia de EPOC en España: relación con hábito tabáquico, tasas de mortalidad y otros determinantes [Geographical differences in the prevalence of COPD in Spain: its relationship with smoking habit, mortality rates and other determinants]. Arch Bronconeumol. 2010;46(10):522-530. doi:10.1016/j.arbres.2010.06.008

11. Løkke A, Lange P, Scharling H, Fabricius P. Developing COPD: a 25 year follow up study of the general population. Thorax. 2006;61(11):935-939. doi:10.1136/thx.2006.062802

12. Miravitlles M, Soler-Cataluña JJ, Calle M, et al. Spanish COPD guidelines (GesEPOC) 2017. Pharmacological treatment of stable chronic obstructive pulmonary disease. Arch Bronconeumol. 2017;53(6):324-335. doi:10.1016/j.arbr.2017.03.017

13. Heatherton TF, Kozlowski LT, Frecker RC. The Fagerström test for nicotine dependence: a revision of the Fagerstrom tolerance questionnaire. $B r$ J Addict. 1991;86(9):1119-1127. doi:10.1111/j.13600443.1991.tb01879.x

14. Herrero MJ, Blanch J, Peri JM, De Pablo J, Pintor L, Bulbena A. A validation study of the hospital anxiety and depression scale (HADS) in a Spanish population. Gen Hosp Psychiatry. 2003;25 (4):277-283. doi:10.1016/S0163-8343(03)00043-4

15. Burgos Rincón F, Casan P. Procedimientos de evaluación de la función pulmonar-II [Procedures to assess lung function-II]. In: Sociedad Española de Neumología y Cirugía Torácica, editor. Manual SEPAR de Procedimientos. Barcelona: Publicaciones Permanyer; 2004.

16. Vestbo J, Hurd SS, Agustí AG, et al. Global strategy for the diagnosis, management, and prevention of chronic obstructive pulmonary disease GOLD executive summary. Am J Respir Crit Care Med. 2013;187(4):347-365. doi:10.1164/rccm.201204-0596PP

17. Guía Española de la EPOC (GesEPOC). Guía de Práctica Clínica para el Diagnóstico y Tratamiento de Pacientes con Enfermedad Pulmonar Obstructiva Crónica (EPOC) [Clinical practice guidelines for the diagnosis and therapy of patients with chronic obstructive lung disease (COPD)]. Available from: https://www.archbronconeu mol.org/es-pdf-S0300289612700352. Accessed August 21, 2020.

18. Rieger-Reyes C, García-Tirado FJ, Rubio-Galán FJ, Marín-Trigo JM. Classification of chronic obstructive pulmonary disease severity according to the new global initiative for chronic obstructive lung disease 2011 guidelines: COPD assessment test versus modified medical research council scale. Arch Bronconeumol. 2014;50 (4):129-134. doi:10.1016/j.arbr.2014.03.003

19. Llauger Rosselló M, Naberan Toña K. GOLD: estrategia mundial para la enfermedad pulmonar obstructiva crónica (EPOC) [GOLD: global strategy for chronic obstructive lung disease (COPD)]. Atención Primaria. 2003;32(5):306-310. doi:10.1016/S0212-6567(03)79280-4

20. Celli BR, Cote CG, Marin JM, et al. The body-mass index, airflow obstruction, dyspnea, and exercise capacity index in chronic obstructive pulmonary disease. $N$ Engl J Med. 2004;350(10):1005-1012. doi:10.1056/nejmoa021322

21. Sobradillo V, Miravitlles M, Jiménez CA, et al. Epidemiological study of chronic obstructive pulmonary disease in Spain (IBERPOC): prevalence of chronic respiratory symptoms and airflow limitation. Arch Bronconeumol. 1999;35(4):159-166. doi:10.1016/ s0300-2896(15)30272-6

22. Díez Piña JM, Quílez Ruíz-Rico N, Bilbao-Goyoaga Arenas T. Smoking cessation clinics as an aid for early diagnosis of chronic obstructive pulmonary disease. Arch Bronconeumol. 2015;51(9):470. doi:10.1016/j.arbr.2014.09.019

23. Johnson KM, Sadatsafavi M, Adibi A, et al. Cost effectiveness of case detection strategies for the early detection of COPD. Appl Health Econ Health Policy. 2020. doi:10.1007/s40258-020-00616-2

24. Çolak Y, Afzal S, Nordestgaard BG, Lange P, Vestbo J. Importance of early COPD in young adults for development of clinical COPD: findings from the Copenhagen general population study. $\mathrm{Am}$ $J$ Respir Crit Care Med. 2020. doi:10.1164/rccm.202003-0532oc 
25. Pezzuto A, Lionetto L, Ricci A, Simmaco M, Borro M. Interindividual variation in CYP2A6 activity and chronic obstructive pulmonary disease in smokers: perspectives for an early predictive marker. Biochim Biophys Acta Mol Basis Dis. 2021;1867(1):165990. doi:10.1016/j.bbadis.2020.165990

26. Pezzuto A, Carico E. Effectiveness of smoking cessation in smokers with COPD and nocturnal oxygen desaturation: functional analysis. Clin Respir J. 2020;14(1):29-34. doi:10.1111/crj.13096

27. Choi JY, Rhee CK. Diagnosis and treatment of early chronic obstructive lung disease (COPD). J Clin Med. 2020;9(11):3426. doi:10.3390/ jem9113426
28. Soriano JB, Zielinski J, Price D. Screening for and early detection of chronic obstructive pulmonary disease. Lancet. 2009;374 (9691):721-732. doi:10.1016/S0140-6736(09)61290-3

29. Riesco JA, Hidalgo M, Chipayo D, Gómez JJ, Zaragozá F. Profile of cardiovascular disease patients who are diagnosed with COPD in a smoking-cessation unit. $A d v$ Ther. 2020;37(8):3562-3570. doi:10.1007/s12325-020-01403-0

\section{Publish your work in this journal}

The International Journal of COPD is an international, peer-reviewed journal of therapeutics and pharmacology focusing on concise rapid reporting of clinical studies and reviews in COPD. Special focus is given to the pathophysiological processes underlying the disease, intervention programs, patient focused education, and self management protocols. This journal is indexed on PubMed Central, MedLine and CAS. The manuscript management system is completely online and includes a very quick and fair peer-review system, which is all easy to use. Visit http://www.dovepress.com/testimonials.php to read real quotes from published authors. 